\section{US space station heads for deep freeze}

\section{Washington}

Bunget pressures on the National Aeronautics and Space Administration (NASA), together with management changes recommended by the Rogers commission and astronauts' heightened concern about safety, are forcing a major rethink of the agency's plan to build a habitable space station by 1994 . NASA Administrator James Fletcher has ordered a thorough re-evaluation of current plans to take account of questions raised both by astronauts and by members of Congress sceptical of the feasibility of the dual-keel design announced in April.

Worries about safety and feasibility have become enmired in a political row over NASA's plan to transfer development of the station's crew modules from Johnson Space Center in Texas to Marshall Space Flight Center in Alabama; much of the criticism of the present design has come from Johnson. The subcommittee in the House of Representatives that oversees NASA has directed the agency to delay implementation of Fletcher's proposals, and congressional representatives from Texas queued up in Congress last week to lambast the new management plan and to demand greater consultation.

The astronauts' primary concerns are that the current design includes no provision for an escape system and that construction will require too much extravehicular activity by astronauts. A simpler one-keel structure could, it is argued, be built at less risk. Astronaut Gordon Fullerton, in a briefing paper for NASA officials, also said that morale on the space station programme is poor and that there is concern that NASA is misrepresenting what it can do to Congress. Fullerton called for development of a new heavy lift vehicle in conjunction with the Department of Defense that would be used to lift the core components on the space station. A radical reappraisal of the space station has also been called for by Senator Spark Matsunaga (Democrat, Hawaii), who favours separate government and commercial stations with different design objectives.

NASA officials say that although reviews of alternative construction plans are in progress, the basic dual-keel design formally proposed to Congress last April still stands. Provision of an escape module or a "safe haven", and a revised construction plan that would allow for earlier use of the space station, are among the options being studied. But Fletcher told Congress last week that the current design could be built only if a fourth shuttle orbiter to replace the Challenger is built. The administration should soon announce how a fourth shuttle would be paid for.

The extent of European participation in the space station is also still far from clear. The European Space Agency (ESA) is adamant that the permanently attached pressurized module for which preliminary design studies were agreed on 1 August

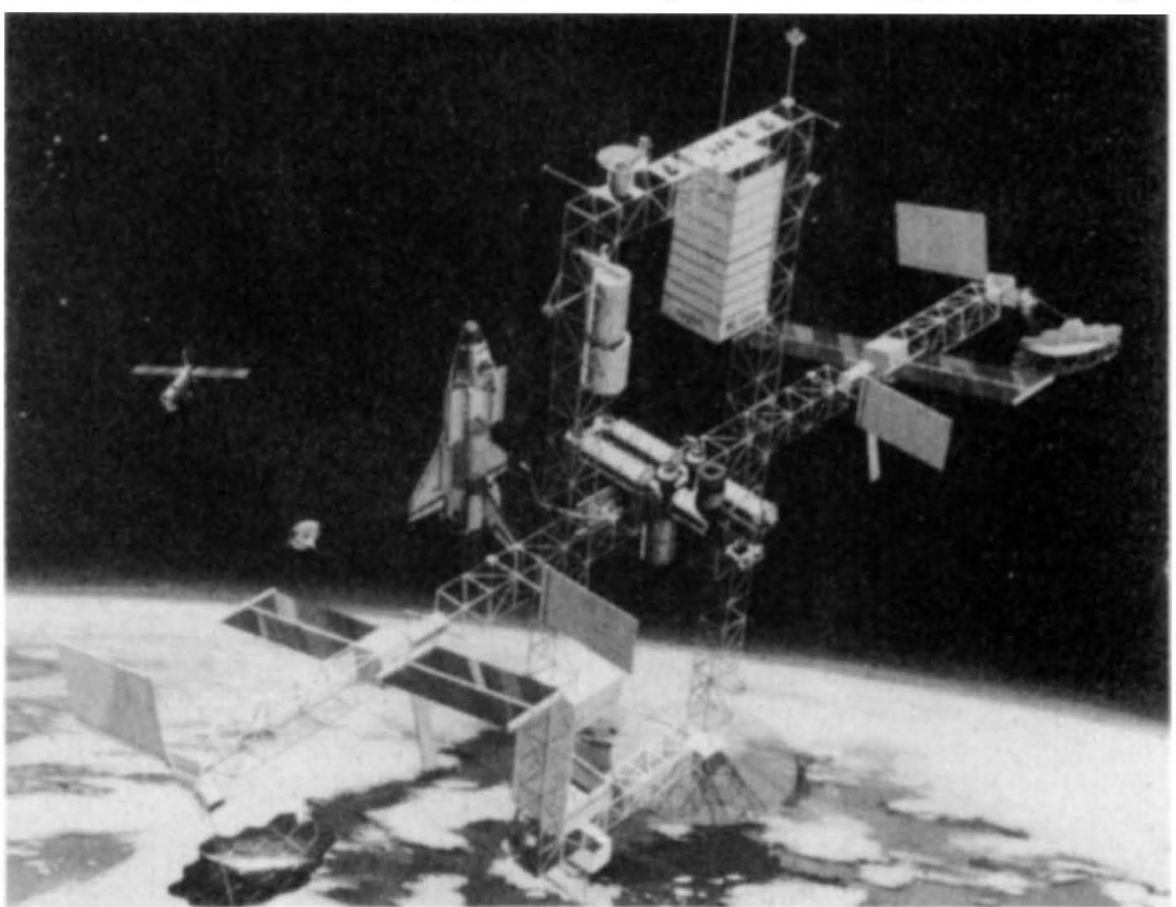

Japanese space plans go ahead

Tokyo

DESPITE uncertainties over the future of the US space station, Japan's Space Activities Commission has just released a report recommending continued "positive" participation. Over the past two fiscal years, Y 5,500 million ( $\$ 36$ million) has been allotted to the design of an experimental space module (above) to be attached to the space station, and the report recommends that construction of its main frame should

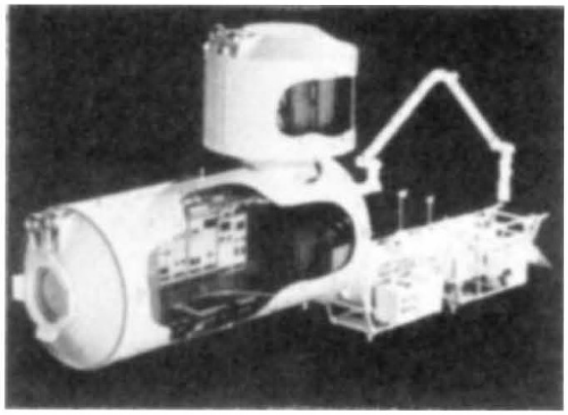

begin in 1989 with a view to launch in 1994.

The module will consist of a pressurized cabin ten metres long for use in experiments on new materials under gravity-free conditions, an exposed service platform equipped with a manipulator and a storage cabin. One or two astronauts will man the station and the report urges the government to begin training in earnest. The estimated cost of the module is $\mathrm{Y350,000}$ million ( $\$ 2,300$ million). David Swinbanks

will be used mainly for materials research, where profitable spin-off technologies are most likely to emerge. But a congressional committee that approves NASA's budget recently recommended that $\$ 150$ million of the $\$ 410$ million sought by the agency for space station development next year should be reserved until certain conditions had been met, among them that ESA's pressurized module will be restricted to life science research.

The 1 August agreement indicates that ESA will also conduct preliminary design work on a man-tended free-flying pressurized module that could dock on the space station, as well as a polar orbiting platform. In return, NASA has agreed that it will study the man-tended free-flyer module jointly with ESA. This is essentially a compromise to allow ESA to continue work on the free flyer, which it has favoured all along as its primary contribution but about which NASA is unenthusiastic. The interim agreement covers only preliminary design.

All concerned acknowledge that the NASA/ESA agreement has merely allowed work to continue and has not resolved fundamental differences of approach between the two sides.

Tim Beardsley 